\title{
The use of antibiotics in the treatment of pediatric varicella patients: real-world evidence from the multi-country MARVEL study in Latin America \& Europe
}

Lara J. Wolfson ${ }^{1 *}$, Marìa Esther Castillo ${ }^{2,3}$, Norberto Giglio ${ }^{4}, Z_{\text {sófia Mészner }}^{5}$, Zsuzsanna Molnár ${ }^{6}$, Mirella Vàzquez ${ }^{7}$, Jacek Wysocki ${ }^{8}$, Alexandra Altland ${ }^{1}$, Barbara J. Kuter ${ }^{9}$, Melissa Stutz $^{10}$, Emmanouil Rampakakis $^{10,11}$ and Craig S. Roberts ${ }^{1}$

\begin{abstract}
Background: Varicella is a highly contagious childhood disease. Generally benign, serious complications necessitating antibiotic use may occur. The objective of this study was to characterize the rate, appropriateness and patterns of realworld antibiotic prescribing for management of varicella-associated complications, prior to universal varicella vaccination (UW) implementation.

Methods: Pooled, post-hoc analysis of 5 international, multicenter, retrospective chart reviews studies (Argentina, Hungary, Mexico, Peru, Poland). Inpatient and outpatient primary pediatric (1-14 years) varicella cases, diagnosed between 2009 and 2016, were eligible. Outcomes, assessed descriptively, included varicella-associated complications and antibiotic use. Three antibiotic prescribing scenarios were defined based on complication profile in chart: evidence of microbiologically confirmed bacterial infection (Scenario A); insufficient evidence confirming microbiological confirmation (Scenario B); no evidence of microbiological confirmation (Scenario C). Stratification was performed by patient status (inpatient vs. outpatient) and country.

Results: Four hundred one outpatients and 386 inpatients were included. Mean (SD) outpatient age was 3.6 (2.8) years; inpatient age was 3.1 (2.8) years. Male gender was predominant. Overall, 12.2\% outpatients reported $\geq 1$ infectious complication, 3.7\% $\geq 1$ bacterial infection, and $0.5 \% \geq 1$ microbiologically confirmed infection; inpatient complication rates were $78.8,33.2$ and $16.6 \%$, respectively. Antibiotics were prescribed to $12.7 \%$ of outpatients and $68.9 \%$ of inpatients. Among users, $\beta$-lactamases (class), and clindamycin (agent), dominated prescriptions. Scenario A was assigned to 3.9\% (outpatients) vs $13.2 \%$ (inpatients); Scenario B: $2.0 \%$ vs. 6.0\%; Scenario C: $94.1 \%$ vs. $80.8 \%$.
\end{abstract}

Conclusions: High rates of infectious complications and antibiotic use are reported, with low rates of microbiological confirmation suggesting possible antibiotic misuse for management of varicella complications.

Keywords: Varicella, Pediatrics, Antimicrobial stewardship, Observation study

\footnotetext{
* Correspondence: lara.wolfson@merck.com

'Merck \& Co., Inc., Center for Observational and Real-World Evidence (CORE),

Kenilworth, NJ, USA

Full list of author information is available at the end of the article
}

(c) The Author(s). 2019 Open Access This article is distributed under the terms of the Creative Commons Attribution 4.0 International License (http://creativecommons.org/licenses/by/4.0/), which permits unrestricted use, distribution, and reproduction in any medium, provided you give appropriate credit to the original author(s) and the source, provide a link to the Creative Commons license, and indicate if changes were made. The Creative Commons Public Domain Dedication waiver (http://creativecommons.org/publicdomain/zero/1.0/) applies to the data made available in this article, unless otherwise stated. 


\section{Background}

Varicella zoster virus (VZV) is a highly contagious disease infecting between 2 and 16 per 1000 individuals annually worldwide [1-3]. Generally, a childhood affliction, regional variations in incidence rates and age distribution are attributed to factors such as population density, climate, and earlier preschool/out-of-home care in children $[4,5]$. Primary symptoms include appearance of a characteristic pruritic vesicular rash, as well as fever, malaise, anorexia, headache, and abdominal pain, occurring either concurrently, or 1-2 days before rash appearance [6].

Although usually following a benign course of disease, varicella can result in serious complications. In pediatric inpatient populations, the most commonly observed are skin and soft tissue infections, and neurological complications [7]. In addition, up to $28 \%$ of varicella outpatients have been found to report complications [8], with skin and soft tissue infections accounting for up to $90 \%$ of these [8]. Consequently, treatment of varicella-related complications in both inpatient and outpatient settings may involve use of antibiotic agents.

Recently, concerns over antimicrobial resistance have increased [9]. Proposed efforts to address resistance include antibiotic stewardship programs, aimed at improving antibiotic use to conserve effectiveness and reduce emergence of resistant strains, and use of vaccines to prevent infections that may result in antibiotic use $[9,10]$. In this context, the purpose of this analysis is to characterize the rate, appropriateness and patterns of antibiotic use for management of varicella-associated complications in realworld clinical settings in the absence of universal varicella vaccination.

\section{Methods}

\section{Study design and patient selection}

This was a post-hoc analysis of 5 multicenter, retrospective chart review studies conducted as part of MARVEL (Multi-country economic and epidemiological burden of varicella). Burden of illness associated with varicella in patients $\leq 14$ years of age was evaluated in Argentina (2009-2014) [8], Hungary (2011-2015) [11], Mexico (2011-2016) [12], Peru (2011-2016) (Castillo M, et al. Economic burden of varicella in children in peru, 20112016, Forthcoming), and Poland (2010-2015) [13]. Each study was approved by local ethics committees, and conducted according to local laws and regulations, as well in accordance with the Guidelines for Good Pharmacoepidemiology Practices (GPP).

Eligible patients were inpatients and outpatients with a primary varicella diagnosis by the pediatrician indicated in their patient chart. Outpatients were those who visited the doctor's office, outpatient clinic/department of hospital, or emergency department (ER) without hospitalization for varicella. Inpatients were defined as those admitted to a hospital for primary varicella, including those initially seen in an outpatient setting.

Patients, in an approximate 1:1 ratio of outpatients to inpatients, were identified by investigators, who screened patient charts in their practices from the most recent year to 5 years previously until the target sample size was reached. The date of the first varicella report was identified, and each chart was reviewed from this date until resolution of disease, or date of last contact, if the resolution date was unavailable. Patients were excluded if they received prior varicella vaccination, presented with a second case of varicella, or had herpes zoster.

\section{Outcome measures}

Sociodemographic characteristics, medical history, as well as disease parameters were extracted from patient charts. Varicella-related clinical complications were identified and profiled by complication type (clinically diagnosed as infectious, non-infectious, or "missing"), infection type (clinically diagnosed as bacterial, nonbacterial [viral, fungal or "other" specified], or missing), and microbiological confirmation (yes/no).

Antibiotics use, defined as type, dose, and duration of use, were obtained from the patient chart from the date of onset to the date of resolution or last patient contact.

\section{Statistical methods}

All analyses were reported for the total cohort, stratified by patient status (outpatient vs. inpatient), and country. Descriptive statistics were produced for all study variables [mean, standard deviation (SD), 95\% confidence interval (CI) of the mean] for continuous variables, and number and percentage for categorical variables.

Distribution of varicella complications was assessed descriptively as the number and proportion of patients with $\geq 1$ clinically diagnosed infectious complication, $\geq 1$ clinically diagnosed bacterial infection, and $\geq 1$ microbiologically confirmed bacterial infection. Proportions by complication type were reported for overall clinically diagnosed infectious complications. All "other" complications were coded using the Medical Dictionary for Regulatory Activities, version 18.0/19.0, and were reported by system organ class.

The number and proportion of patients reporting use of $\geq 1$ antibiotic was ascertained. Among antibiotic users, the mean number of antibiotics prescribed and duration of use (days), was assessed. Additionally, the number and proportion of patients prescribed $\geq 1$ antibiotic by class and top 5 agents (within the pooled cohort) was evaluated.

Data collected did not allow for a direct link between infection type and antibiotic prescribed. Instead, antibiotic users were classified as having received antibiotics under 4 prescribing scenarios based on their 
complication profile present in the patient chart (see Additional file 1: Table S1 for the classification algorithm):

Scenario A: evidence of a confirmed bacterial infection (clinically diagnosed and microbiologically confirmed)

Scenario B: insufficient evidence to confirm/refute bacterial infection

Scenario C: antibiotic prescribed without information confirming a bacterial infection

Scenario D: potentially redundant antibiotic use, defined as number of antibiotics prescribed greater than the number of infectious complications.

The relationship between the number and proportion of antibiotic users by prescribing scenarios was reported to understand the potential inappropriate use of antibiotics (scenarios B, C and D). In addition, for patients classified according to Scenario $C$ and Scenario $B / C$, the number and proportion reporting $\geq 1$ antibiotic by class and agent was assessed.

Cumulative number of days of annual VZV-related antibiotic use was calculated based on previous estimates for the number of inpatient and outpatient cases of varicella by country $[8,11-13]$, as well as the proportion of patients administered antibiotics, and the corresponding mean duration of use, calculated as per described above.

Statistical analyses were performed using $\mathrm{SAS}^{\circ}$ software version 9.4 (SAS Institute Inc., Cary, NC, USA).

\section{Results}

\section{Baseline patient and disease characteristics}

The total cohort included 787 patients (401 outpatients and 386 inpatients), distributed across the following locations: Argentina $(n=150,19.1 \%)$; Hungary $(n=156$, $19.8 \%)$; Mexico ( $n=152$ (19.3\%); Peru $(n=179,22.7 \%)$ and Poland $(\mathrm{n}=150 ; 19.1 \%)$. Mean (SD) age in the total outpatient population was 3.6 (2.8) years; inpatients were found to be slightly younger that outpatients [mean (SD): 3.1 (2.8) years], and included more males (50.6\% outpatients, 56.7\%, inpatients) (Table 1).

Based on the maximum number of skin lesions reported, there was more severe disease among inpatients, with over $35 \%$ reporting $\geq 250$ lesions, compared to < $15 \%$ of outpatients. A compromised immune system was identified for 11 inpatients (2.8\%) and 2 outpatients (0.5\%) (Table 1).

\section{Varicella-associated complications}

In the combined analysis, $12.2 \%$ of outpatients reported $\geq 1$ infectious complication, of which $3.7 \%$ were

Table 1 Baseline patient and disease characteristics by patient status and country

\begin{tabular}{|c|c|c|c|c|c|c|c|c|c|c|c|c|}
\hline & \multicolumn{6}{|c|}{ Outpatients } & \multicolumn{6}{|l|}{ Inpatients } \\
\hline & Argentina & Hungary & Mexico & Peru & Poland & Total & Argentina & Hungary & Mexico & Peru & Poland & Total \\
\hline & $N=75$ & $N=75$ & $N=75$ & $N=101$ & $N=75$ & $N=401$ & $N=75$ & $N=81$ & $N=77$ & $N=78$ & $N=75$ & $N=386$ \\
\hline Gender, male, n (\%) & $40(53.3)$ & $33(44.0)$ & $31(41.3)$ & $58(57.4)$ & $41(54.7)$ & $203(50.6)$ & $46(61.3)$ & 45 (55.6) & $39(50.6)$ & $43(55.1)$ & $46(61.3)$ & $219(56.7)$ \\
\hline Age, years, mean (SD) & $3.8(2.4)$ & $4.4(2.0)$ & $3.0(3.2)$ & $3.3(3.3)$ & $3.9(2.6)$ & $3.6(2.8)$ & $2.9(2.2)$ & $3.7(2.1)$ & $2.6(3.5)$ & $2.4(3.4)$ & $4.2(2.3)$ & $3.1(2.8)$ \\
\hline \multicolumn{13}{|l|}{ Race, n (\%) } \\
\hline Caucasian & $4(5.3)$ & $75(100)$ & $2(2.7)$ & - & $75(100)$ & $156(38.9)$ & $7(9.3)$ & $81(100)$ & $3(3.9)$ & $2(2.6)$ & $75(100)$ & $168(43.5)$ \\
\hline Hispanic/Latino & $71(94.7)$ & - & $61(81.3)$ & $90(89.1)$ & - & $222(55.4)$ & $68(90.7)$ & - & 69 (89.6) & $46(59.0)$ & - & $183(47.4)$ \\
\hline $\begin{array}{l}\text { Latino/Mestizo/ } \\
\text { Indigenous }\end{array}$ & - & - & $12(16.0)$ & $11(10.9)$ & - & $23(5.7)$ & - & - & $5(6.5)$ & $30(38.5)$ & - & $35(9.1)$ \\
\hline \multicolumn{13}{|l|}{ Area of residence, n (\%) } \\
\hline Rural & $4(5.3)$ & $4(5.3)$ & $13(17.3)$ & $4(4.0)$ & $7(9.3)$ & $32(8.0)$ & $12(16.0)$ & $28(34.6)$ & $16(20.8)$ & $23(29.5)$ & $23(30.7)$ & $102(26.4)$ \\
\hline Urban & $70(93.3)$ & $71(94.7)$ & $62(82.7)$ & $97(96.0)$ & $64(85.3)$ & $364(90.8)$ & $62(82.7)$ & $53(65.4)$ & $61(79.2)$ & $55(70.5)$ & $51(68.0)$ & $282(73.1)$ \\
\hline Not available & $1(1.3)$ & - & - & - & $4(5.3)$ & $5(1.2)$ & $1(1.3)$ & - & - & - & $1(1.3)$ & $2(0.5)$ \\
\hline \multicolumn{13}{|c|}{ Maximum number of skin lesions, n (\%) } \\
\hline$<50$ & $20(26.7)$ & $51(68.0)$ & $27(36.0)$ & $56(55.4)$ & $25(33.3)$ & $179(44.6)$ & $3(4.0)$ & $2(2.5)$ & $20(26.0)$ & $1(1.3)$ & $18(24.0)$ & $44(11.4)$ \\
\hline $50-249$ & $36(48.0)$ & $16(21.3)$ & $44(58.7)$ & $35(34.7)$ & $36(48.0)$ & $167(41.6)$ & $50(66.7)$ & $59(72.8)$ & $45(58.4)$ & $7(9.0)$ & $37(49.3)$ & $198(51.3)$ \\
\hline $250-500$ & 17 (22.7) & $7(9.3)$ & $4(5.3)$ & 9 (8.9) & 14 (18.7) & $51(12.7)$ & 14 (18.7) & $20(24.7)$ & $11(14.3)$ & $50(64.1)$ & $12(16.0)$ & $107(27.7)$ \\
\hline$>500$ & $2(2.7)$ & $1(1.3)$ & - & $1(1.0)$ & - & $4(1.0)$ & $8(10.7)$ & - & $1(1.3)$ & $20(25.6)$ & $8(10.7)$ & $37(9.6)$ \\
\hline $\begin{array}{l}\text { Immuno-compromised, } \\
\text { yes, n (\%) }\end{array}$ & $1(1.3)$ & - & $1(1.3)$ & - & - & $2(0.5)$ & $1(1.3)$ & $4(4.9)$ & $5(6.5)$ & $1(1.3)$ & - & $11(2.8)$ \\
\hline
\end{tabular}


a Proportion of outpatients reporting infectious complications by type

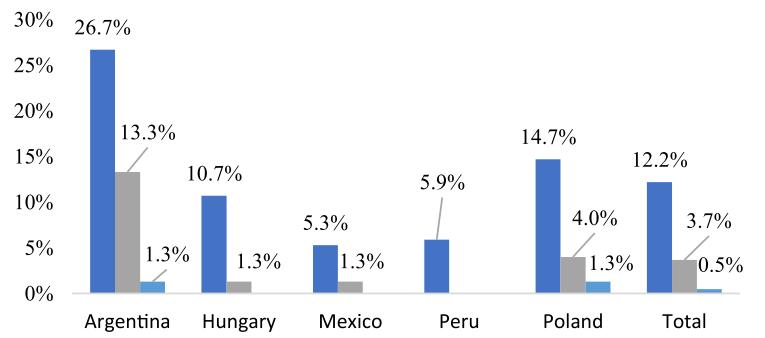

b Proportion of inpatients reporting infectious complications by type

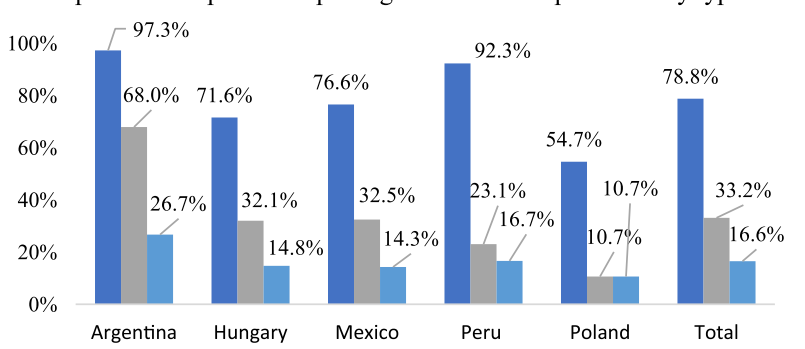

- $\geq 1$ infectious complication

- $>=1$ bacterial infection

- $\geq 1$ microbiologically confirmed bacterial infection

C Types of complications associated with varicella by country for outpatients *

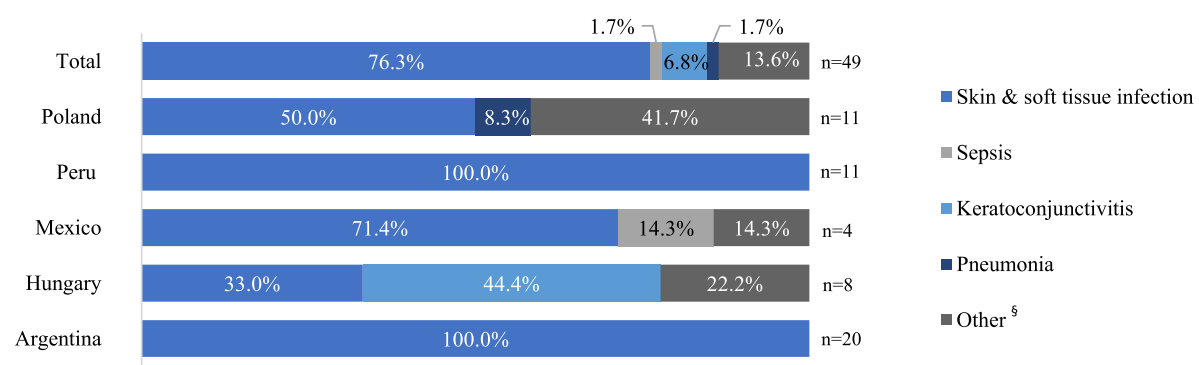

d Types of complications associated with varicella by country for inpatients*

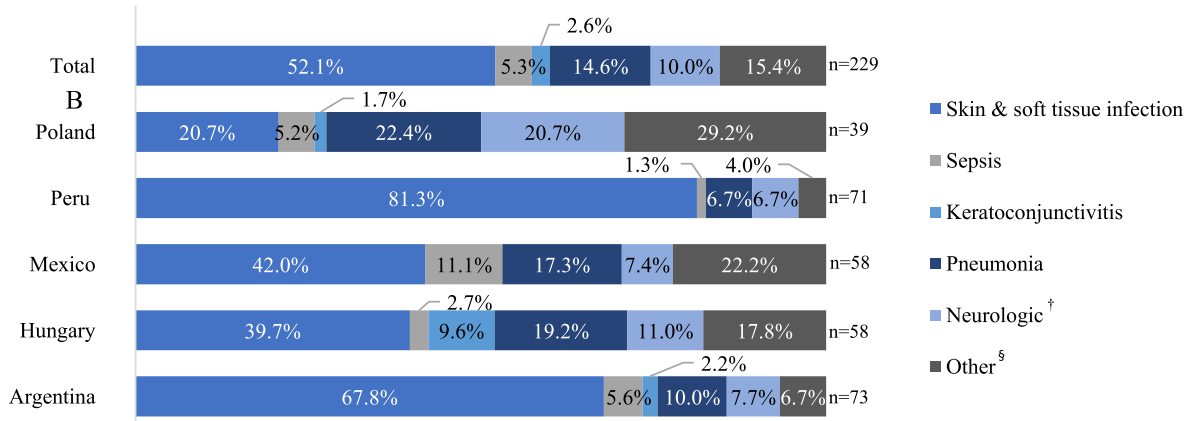

Fig. 1 Infectious complications by patient status and country. * Proportions based on total number of infectious complications; patients may have reported $\geq 1$ infectious complication. ${ }^{* *}$ One outpatient was diagnosed with sepsis and died in the ER due to varicella-related toxic shock without hospital admission. ${ }^{\S}$ Other includes: nephritis, meningitis, hepatitis, acute osteomyelitis, septic arthritis and "other" complication categories. ${ }^{\dagger}$ Neurologic includes: encephalitis and cerebellitis

identified as bacterial, and a further $0.5 \%$ were microbiologically confirmed bacterial infections (Fig. 1a). Inpatient rates reported for $\geq 1$ infectious, bacterial, and microbiologically confirmed bacterial infections were 78.8, 33.2 and $16.6 \%$, respectively (Fig. 1b). The highest proportion of complications was observed in Argentina (Fig. $1 \mathrm{a}$ and b).
Skin and soft tissue infection was found to be the most common varicella-related complication accounting for $76.3 \%$ of outpatient (Fig. 1c) and 52.1\% of inpatient (Fig. 1d) infectious complications, respectively, followed by sepsis (outpatients: $1.7 \%$, inpatients: $5.3 \%$ ), keratoconjunctivitis $(6.8 \%, 2.6 \%)$, pneumonia $(1.7 \%, 14.6 \%)$, neurologic $(10.0 \%$; inpatients only), and "other" complications (13.6\%, 15.4\%). 


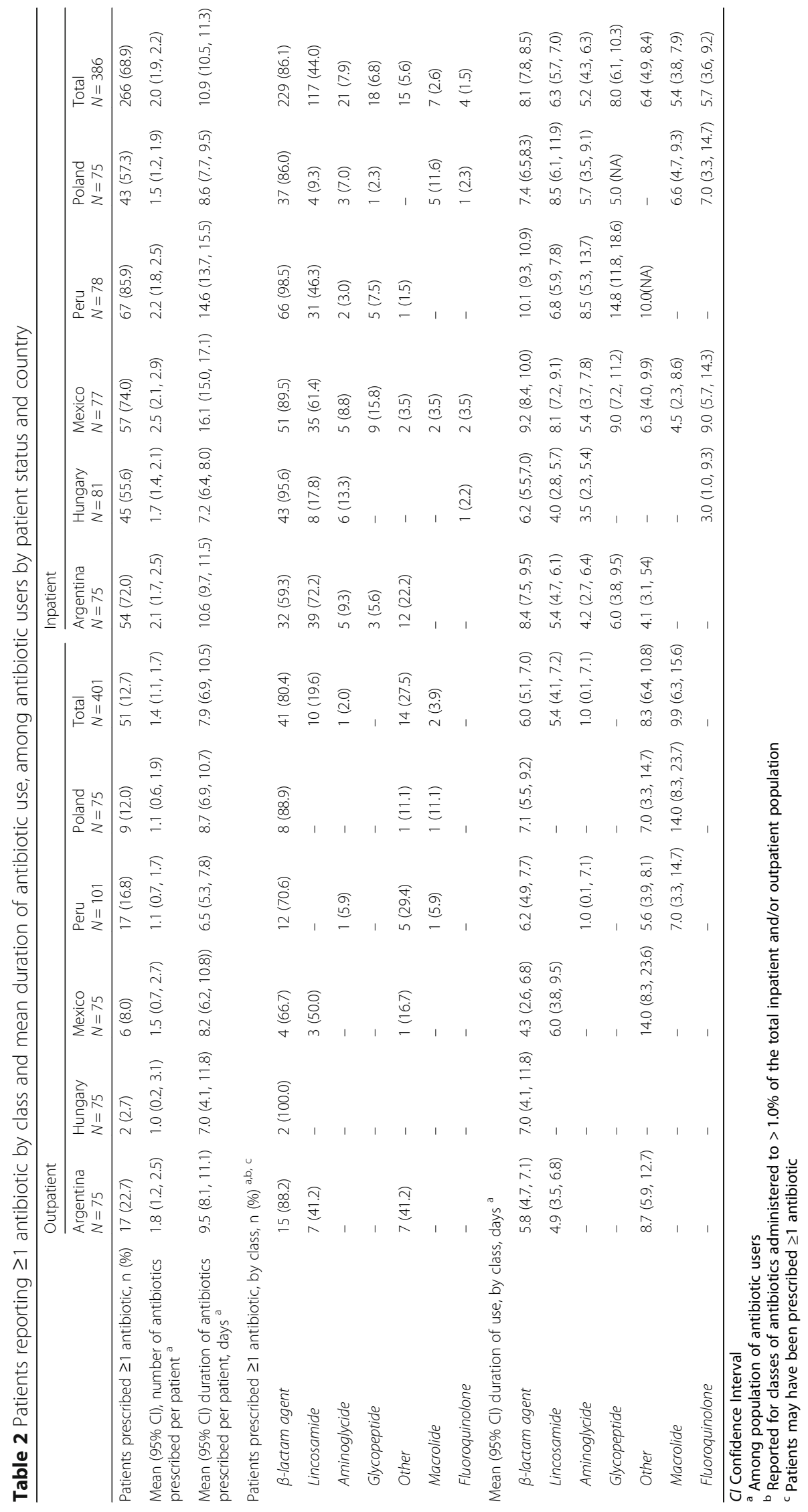




\section{Antibiotic use}

The proportion reporting use of $\geq 1$ antibiotic was $12.7 \%$ $(n=51 / 401)$ among outpatients and 68.9\% $(n=266 / 386)$ among inpatients (Table 2). Mean (95\% CI) number of antibiotics prescribed among users was highest in Latin American inpatients [Argentina: 2.1 (1.7, 2.5); Mexico: 2.5 (2.1, 2.9); Peru: $2.2(1.8,2.5)]$, as was duration of antibiotic use $[10.6$ (9.7, 11.5); 16.1 (15.0, 17.1); 14.6 $(13.7,15.5)$ days, respectively]. Overall outpatient [mean $(95 \% \mathrm{CI})]$ estimates were lower for both number of antibiotics prescribed $[1.4(1.1,1.7)]$ and duration of use $[7.9$ $(6.9,10.5)]$ days (Table 2$)$.

Among antibiotic users, prescriptions by antibiotic class involved predominantly $\beta$-lactam agents for all countries, with the exception of Argentinian inpatients, where $72.2 \%$ were administered lincosamide class antibiotics $(n=39 / 54)$. Generally, lincosamides were 2 nd after $\beta$-lactam agents in terms of frequency of use in inpatients (Table 2). Overall mean (95\% CI) duration of use of $\beta$-lactam agents was $6.0(5.1,7.0)$ days for outpatients, and $8.1(7.8,8.5)$ days for inpatients; lincosamide duration of use was slightly lower at 5.4 $(4.1,7.2)$ days and 6.3 (5.7, 7.0) days for outpatients and inpatients, respectively.

The top 5 antibiotic agents identified among users were clindamycin (19.6\% outpatients; $44.0 \%$ inpatients); ceftriaxone $(13.7 \% ; 16.9 \%)$, cefuroxime $(3.9 \% ; 15.8 \%)$, penicillin $(11.8 \% ; 14.7 \%)$ and cefalexin $(11.8 \% ; 14.7 \%)$; both Hungarian and Polish inpatients, however, reported cefuroxime as the leading antibiotic agent prescribed, [24.4\% $(n=11 / 45), 53.5 \%(=23 / 43)]$, respectively] (Additional file 2: Table S2). Highest outpatient duration of use was for cefalexin $[7.1(4.7,10.6)$ days], whereas highest inpatient duration was for penicillin $[6.7(5.8,7.7)$ days].

Extrapolated to the annual number of VZV-related pediatric inpatients and outpatients per country, cumulative duration of VZV-related antibiotic use per year was lowest in Hungary and Mexico at 77, 871 and 287, 528 days, respectively, and highest in Peru $(\sim 1.6$ million days) Poland $(\sim 1.8$ million days, $)$ and Argentina $(\sim 2.6$ million days) (Additional file 3: Table S3).

\section{Prescribing scenarios}

Overall, 3.9\% of antibiotic-treated outpatients (Fig. 2a) and $13.2 \%$ of inpatients (Fig. 2b) were classified according to Scenario A (confirmed infection), whereas Scenario B (insufficient evidence) was assigned to 2.0 and $6.0 \%$, respectfully. The vast majority of patients did not have sufficient information in their chart to confirm/refute bacterial infection, classified according to Scenario C (94.1\% outpatients vs. $80.8 \%$ inpatients). Scenario C was most prevalent in Poland (20.9\%), with Scenario A highest in Peru (19.4\%) and Mexico (14.0\%). Scenario D (possible redundant use), was identified for over $40 \%$ of Argentinian, Mexican and Peruvian patients, regardless of status, (Fig. 2c), with an overall prevalence of $43.1 \%$ in outpatients and $50.4 \%$ in inpatients.

Antibiotic use in the population of patients prescribed antibiotics according to Scenario C (total $n=17$ ) and Scenario $\mathrm{B} / \mathrm{C}$ (total $n=280$ ) is presented in Table 3. Similar to the findings in the overall population of antibiotic users, $\beta$-lactam agents accounted for the majority of antibiotics, by class, prescribed to Scenario $C[87.5 \%$ of inpatients $(n=14 / 16)$ ], and Scenario B/C populations [outpatients: 81.6\% $(n=40 / 49)$; inpatients: $85.7 \% \quad(n=198 / 231)]$ (Table 3). Clindamycin was the most commonly prescribed Scenario B/C agent for both outpatients (18.4\%; $n=9 / 51)$ and inpatients $(42.0 \% ; n=97 / 231)$ with cefuroxime the most common inpatient antibiotic under Scenario C $(n=5 / 16 ; 31.3 \%)$ (Additional file 4: Table S4).

Overall mean $(95 \% \mathrm{CI})$ duration of use of antibiotics prescribed according to Scenario C was $7.0(3.3,14.7)$ days and $5.5(4.2,7.2)$ days for outpatients and inpatients, respectively; for Scenario $\mathrm{B} / \mathrm{C}$ classified antibiotics, duration was $7.9(6.8,9.0)$ days in outpatients, and $10.4(10.0,10.9)$ days in inpatients (Table 3$)$.

\section{Discussion}

The results of this study demonstrate that, among pediatric varicella cases in the 5 studied countries, rates of infectious complications in outpatient (12.2\%) and inpatient $(78.8 \%)$ settings are considerable, with approximately $33 \%$ of all inpatient complications involving a bacterial infection, of which $>15 \%$ were confirmed microbiologically. Consequently, almost $70 \%$ of the inpatient cohort, and an additional $12.7 \%$ of outpatients, were prescribed $\geq 1$ antibiotic agent for the treatment of varicella-related complications, for which skin and soft tissue infections were predominant.

It is estimated that between 37 and $78 \%$ of all-cause pediatric hospital visits worldwide, and $20 \%$ of pediatric ambulatory care setting consultations, result in an antibiotic prescription [14-16]. This not only makes antibiotics the highest prescribed drugs in hospital settings [16], but also predisposes to inappropriate prescribing practices, both with respect to the treatment of nonbacterial infections, as well as the misuse of broad spectrum antibiotics, contributing to antibiotic resistance $[15,16]$.

The top five most commonly prescribed antibiotic agents, in this pooled population, were clindamycin, ceftriaxone, cefuroxime, penicillin, and cefalexin, with $\beta$ lactam agents consistently identified as the most frequently prescribed class. These findings are consistent with the Worldwide Antibiotic Resistance and Prescribing in European Children (ARPEC) point prevalence survey, which ascertained inpatient pediatric antibiotic 
a Outpatients administered antibiotics under Prescribing Scenario A-C*

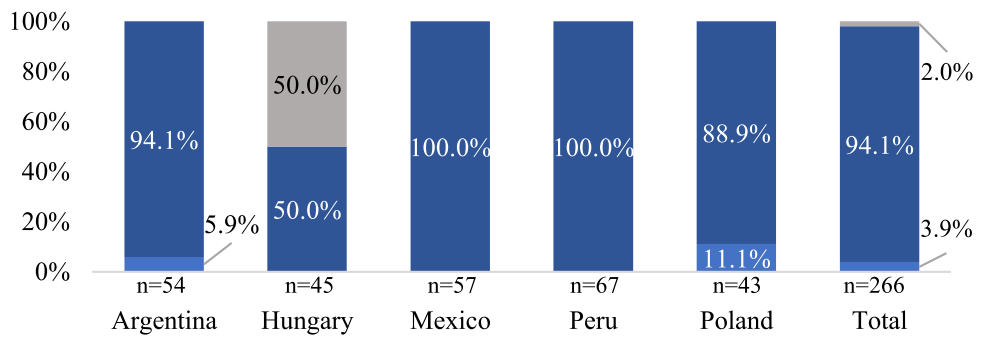

b Inpatients administered antibiotics under Prescribing Scenario A-C*

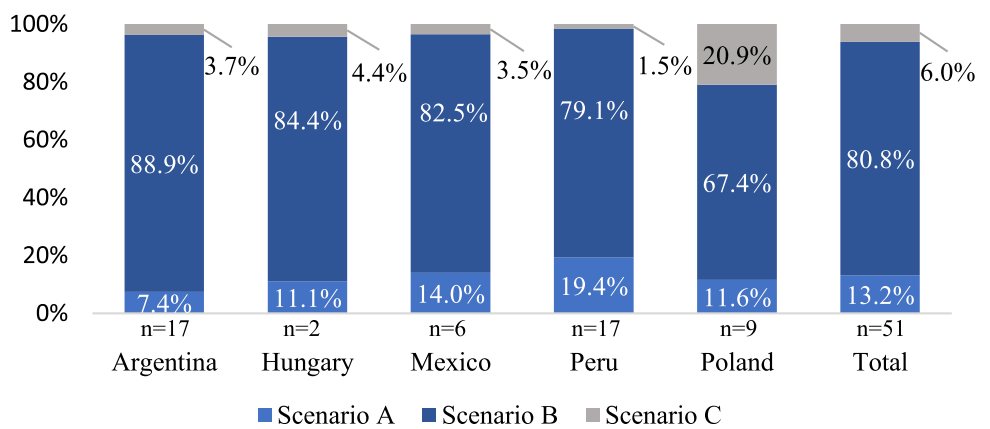

c Prescribing Scenario D* among antibiotic users by patient status

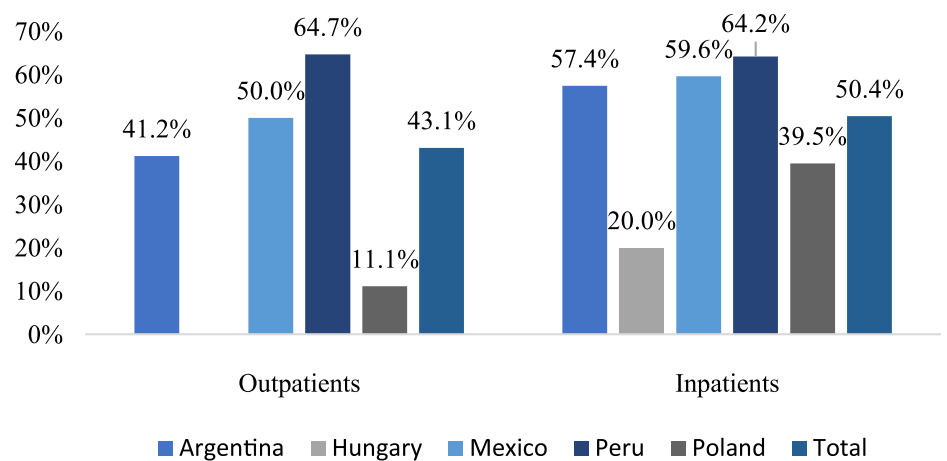

Fig. 2 Antibiotic prescribing scenarios by patient status and country. *Prescribing Scenarios based on definitions provided in Additional file 1: Table S1

prescribing patterns across 41 countries [14]. Results of ARPEC found $\beta$-lactam agents to account for over $50 \%$ of all antibiotic prescriptions across all regions, except North America. In addition, by agent, Eastern European estimates for antibiotic use, which encompasses both Poland and Hungary, confirm ceftriaxone as the most prescribed antibiotic within this region; Latin American antibiotic use included ceftriaxone and clindamycin within the top four below meropenem (1st) and vancomycin (2nd) [14].

As the initial study design did not allow for a definitive link to be made between complication and antibiotic, an exact post-hoc classification of antibiotic use was not possible. Instead, to approximate antibiotic prescribing patterns, a set of conservative assumptions were implemented, guiding patient classification into four prescribing scenarios. Consequently, the majority of patients were administered antibiotics without sufficient data in their patient chart to confirm/refute microbiological confirmation (Scenario B), accounting for just over $80 \%$ of inpatients and $94.1 \%$ of outpatients. Patients under Scenario C (approximation to 'inappropriate use') accounted for $6 \%$ of inpatients and $2 \%$ of outpatients. Recent studies report between 33 and $50 \%$ of in-hospital pediatric antibiotic prescriptions are deemed inappropriate [17-19], with a U. S pediatric primary care setting reporting 30\% [20]. The rates reported in the present study likely underrepresent the true magnitude of inappropriate and appropriate prescribing practices, the latter represented by patients under Scenario A (3.9\% of outpatients; $13.2 \%$ of inpatients). In interpreting the rates of possibly inappropriate antibiotic use, one needs 


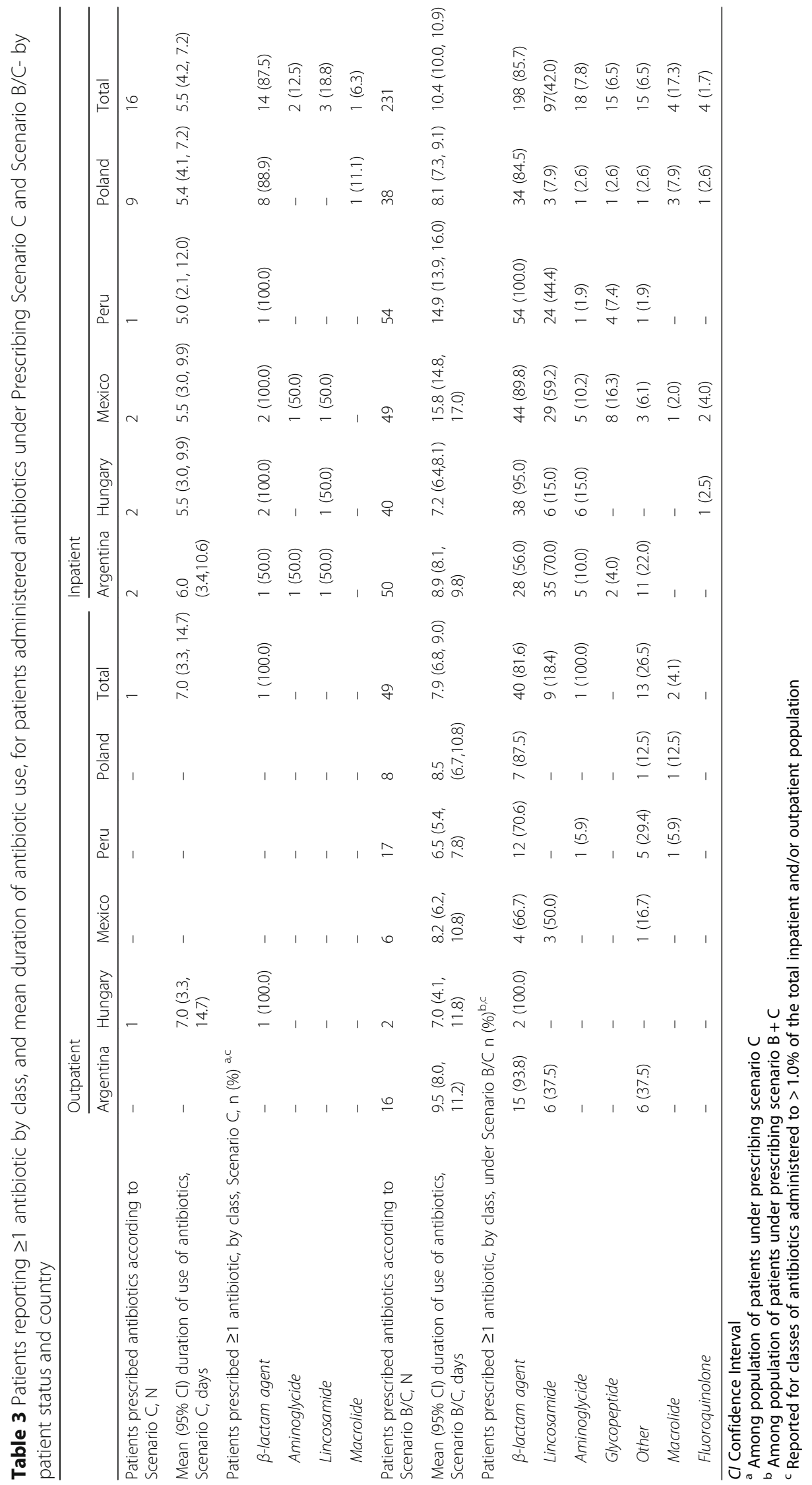


to take into consideration that for skin and soft tissue infections, the most frequent complications described here, bacteriological isolation is difficult, and the diagnosis is mainly clinical; furthermore, microbiological evidence suggests that complicated skin and soft tissue infections are predominantly associated with Grampositive bacteria for which antibiotic treatment is indicated [21]. Similarly, for pneumonia which may be caused by bacteria whose isolation is difficult, diagnosis is mainly based on clinical, laboratory or radiographic evidence which are often sufficient for antibiotic treatment.

Although the majority of children managed in an outpatient setting did not require antibiotic treatment, antibiotic use in the 5 studied countries was high, and the annual estimated number of cumulative days of antibiotic use was found to range from approximately 80,000 days in Hungary to over 2.5 million days in Argentina. Antimicrobial resistance (AMR) a serious worldwide health problem, has the potential to transform common pathogens into dangerous infections [22]. Latin America reports elevated rates of AMR for pathogens involved in respiratory tract infection, such as S. pneumoniae [23, 24]. This is in addition to the extremely high burden of multi-drug resistance tuberculosis in Peru [25]. Avoidance of additional antibiotic burden warrants consideration, particularly if vaccine-preventable. In fact, vaccines that can prevent bacterial infections, or viral infections that can result in bacterial complications, represent a potential tool in antimicrobial stewardship programmes, fighting resistance by limiting spread of disease. This is exemplified by pneumococcal conjugate vaccines, which contributed to the decline of invasive pneumococcal disease in Europe, as well as rates of AMR [26].

The burden of varicella may also be addressed through immunization programs. Monovalent or combination (measles, mumps, rubella, and varicella; MMRV) varicella- containing vaccines are approved in immunocompetent children $\geq 12$ months of age in each of the five countries studied [27]; Argentina introduced universal varicella vaccination in 2015, Peru in 2018, and Hungary announced their intention to introduce universal varicella vaccination starting in 2019. Varicella vaccines have been consistently shown in clinical trials and observational studies to be well tolerated and effective in preventing disease transmission [28]. Notwithstanding, only about 40 countries around the world have implemented universal varicella vaccination programmes [29]. In countries adopting universal varicella vaccination, dramatic declines in varicella incidence and associated morbidity and mortality have been reported [28, 30].

The current findings should be interpreted in consideration of the study limitations. A major limitation of the current study, as discussed above, relates to the fact that the post-hoc study design prevented a definitive link between antibiotic use and type of complication. Consequently, definitive "use classification" could not be assigned, and the assumptions implemented may have resulted in over or underestimation of rates across different prescribing scenarios. A further limitation is related to the assessment of antibiotic use by class and agent: as prescribing patterns are subject to regional variations and differences in clinical practice guidelines, the rates observed for the total inpatient and outpatient populations may be skewed due to inconsistencies in prescribing practices across countries. Furthermore, the slightly higher number of outpatients in Peru may have skewed the results for the total outpatient population towards the Peruvian data. The lack of information about the type of pathogens and antibiotic susceptibility is another constraint. Finally, the retrospective chart review design of the individual studies contributes to 1) a selection bias due to an overrepresentation of care-seekers, potentially including a subset of patients with more severe disease, 2) an information bias, as data extracted from medical charts is subject to missing, inconsistent or erroneous information, and human error during transcription.

\section{Conclusions}

Regardless of limitations, the reported high rates of infectious complications and antibiotic use are indicative of high varicella-associated patient, caretaker, and healthcare burden $[8,11]$ as well as increased risk for antibiotic resistance, both of which could be averted through universal varicella vaccination; whereas the low rates of documented microbiological confirmation possibly suggest considerable antibiotic misuse for management of varicella complications. Antimicrobial stewardship programmes should be coupled with treatment modalities that prevent the spread of infectious diseases which either directly or indirectly necessitate antibiotic treatment.

\section{Additional files}

Additional file 1: Table S1. Definitions of Prescribing Scenarios by Complication Profile. (DOCX $16 \mathrm{~kb}$ )

Additional file 2: Table S2. Patients reporting $\geq 1$ antibiotic by agent and mean duration of antibiotic use, among antibiotic users by patient status and country (DOCX $24 \mathrm{~kb})$

Additional file 3: Table S3. Cumulative Days of Antibiotic Use by Country based on Annual Number of Pediatric Varicella Cases (DOCX 21 kb)

Additional file 4: Table S4. Patients reporting $\geq 1$ antibiotic by agent, and mean duration of antibiotic use, for patients administered antibiotics under Prescribing Scenario C and Scenario B/C- by patient status and country (DOCX $20 \mathrm{~kb})$

Abbreviations

AMR: antimicrobial resistance; ARPEC: Worldwide Antibiotic Resistance and Prescribing in European Children; Cl: confidence interval; SD: standard deviation; UW: universal varicella vaccination; VZV: varicella zoster virus 


\section{Acknowledgements}

The authors would like to acknowledge all principal investigators for their contribution to the studies in each country.

\section{Authors' contributions}

LWW conceived/designed the study, analyzed the data, interpreted the results, created figures, and reviewed/revised the manuscript. MEC, NG, ZM, $\mathrm{ZM}, \mathrm{MV}$, and JW collected the data, interpreted the results, and reviewed/ revised the manuscript. AA, BJK and CSR interpreted the results and reviewed/revised the manuscript. MS analyzed the data, interrupted the results, and wrote the manuscript. ER conceived/designed the study, analyzed the data, interpreted the results, and wrote the manuscript. All authors reviewed and approved the final manuscript.

\section{Funding}

Merck \& Co., Inc. provided the funds to conduct this study. Merck \& Co., Inc. participated in the design of the study, interpretation of the data, and critical review/approval of the manuscript.

\section{Availability of data and materials}

The datasets generated and/or analysed during the current study are not publicly available due to ethical reasons, to ensure the privacy of the patient level data utilized in the current study but are available from the corresponding author on reasonable request.

\section{Ethics approval and consent to participate}

In line with the local regulations, notification to the central Ethics Committee was done for all participating sites. Approval was obtained from the following ethics committees: Urząd Rejestracji Produktów Leczniczych, Wyrobów Medycznych i Produktów Biobójczych, Centralna Ewidencja Badań Klinicznych [Poland]; Secretaría de Salud, Hospital del Niño Morelense, Dirección de División Médica, Dirección de Unidad de Enseñanza e Investigación, Comité de Investigación, Instituto Nacional de Pediatría, Hospital Médica Sur, Hospital de Especialidades del Niño y la Mujer, Hospital del Niño y el Adolescente Morelense, y el Centro de Investigación Farmacéutica Especializada [Mexico]; Ministerio de Salud, Instituto de Gestión de Servicios de Salud, Instituto Nacional de Salud del Niño - Breña [Peru]; Egészségügyi Tudományos Tanács Tudományos és Kutatásetikai Bizottság (ETT TUKEB), Egészségügyi Tudományos Tanács Titkárság [Hungary]; Institutional Review Board, Jordan University of Science and Technology, King Abdulla University Hospital [Jordan]; Ministerio de Salud - GCABA, Dirección General de Docencia e Investigación [Argentina]. Patient consent was not required, as data were collected retrospectively and provided by the treating physicians in an anonymous manner, identified only by an encrypted patient number.

\section{Consent for publication}

Not applicable.

\section{Competing interests}

Dr. Wolfson is an employee and stockholder of Merck \& Co. Dr. Castillo, Dr. Gilgio, Dr. Meszner, Dr. Vàsquez, Dr. Molnár, and Dr. Wysocki all report personal fees from Merck \& Co. during the conduct of the study. In addition, Dr. Giglio reports personal fees from GSK outside of the submitted work; Dr. Mészner reports grants and personal fees from MSD, Pfizer, and GSK outside the submitted work; Dr. Wysocki reports grants from Sanofi during the conduct of the study, as well as grants and personal fees from Pfizer outside the submitted work. Ms. Altland, Dr. Kuter, and Dr. Roberts are employees of Merck \& Co. Dr. Rampakakis reports 'other' conflict from Merck \& Co., Inc., during the conduct of the study, and is an employee of JSS Medical Research, the CRO hired to manage the MARVEL studies and provide biostatistics and medical writing services. Ms. Stutz is an employee of JSS Medical Research.

\section{Author details}

'Merck \& Co., Inc., Center for Observational and Real-World Evidence (CORE), Kenilworth, NJ, USA. ${ }^{2}$ Instituto Nacional de Salud del Niño (INSN), Breña, Perú. ${ }^{3}$ Universidad Peruana Cayetano Heredia, Lima, Perú. ${ }^{4}$ Hospital de Niños Ricardo Gutiérrez, Buenos Aires, Argentina. ${ }^{5}$ St. László Hospital for Infectious Diseases, National Institute of Child Health, Budapest, Hungary. ${ }^{6}$ National Center for Epidemiology, Budapest, Hungary. ${ }^{7}$ Instituto Nacional de Pediatría,
Ciudad de México, México. ${ }^{8}$ Poznan University of Medical Sciences, Poznan, Poland. ${ }^{9}$ Merck \& Co., Inc., Global Vaccines Medical Affairs, Kenilworth, NJ, USA. ${ }^{10}$ JSS Medical Research, Montréal, Québec, Canada. ${ }^{11}$ Department of Pediatrics, McGill University, Montréal, Québec, Canada.

\section{Received: 5 February 2019 Accepted: 29 May 2019}

Published online: 26 June 2019

\section{References}

1. Bardach A, Cafferata ML, Klein K, et al. Incidence and use of resources for chickenpox and herpes zoster in Latin America and the Caribbean-a systematic review and meta-analysis. Pediatr Infect Dis J. 2012;31:1263-8.

2. Heininger U, Seward JF. Varicella. Lancet. 2006;368:1365-76.

3. Sadzot-Delvaux C, Rentier B, Wutzler P, et al. Varicella vaccination in Japan, South Korea, and Europe. J Infect Dis. 2008;197(Suppl 2):S185-S90.

4. Lolekha S, Tanthiphabha W, Sornchai P, et al. Effect of climatic factors and population density on varicella zoster virus epidemiology within a tropical country. Am J Trop Med Hyg. 2001;64:131-6.

5. Yawn BP, Yawn RA, Lydick E. Community impact of childhood varicella infections. J Pediatr. 1997:130:759-65.

6. Arvin AM. Varicella-zoster virus. Clin Microbiol Rev. 1996;9:361-81.

7. Ziebold C, von Kries R, Lang R, et al. Severe complications of varicella in previously healthy children in Germany: a 1-year survey. Pediatrics. 2001;108:E79.

8. Giglio N, Monsanto H, Rampakakis E, et al. Economic burden of varicella in children 1-12 years of age in Argentina, 2009-2014. J Med Econ. 2018;21(4): 416-424.

9. Barlam TF, Cosgrove SE, Abbo LM, MacDougall C, Schuetz AN, Septimus EJ, Srinivasan A, Dellit TH, Falck-Ytter YT, Fishman NO, et al. Implementing an Antibiotic Stewardship Program: Guidelines by the Infectious Diseases Society of America and the Society for Healthcare Epidemiology of America. Clinical infectious diseases: an official publication of the Infectious Diseases Society of America. 2016;62(10):e51-77.

10. Jansen KU, Knirsch C, Anderson AS. The role of vaccines in preventing bacterial antimicrobial resistance. Nat Med. 2018:24:10-9.

11. Meszner Z, Molnar Z, Rampakakis E, et al. Economic burden of varicella in children 1-12 years of age in Hungary, 2011-2015. BMC Infect Dis. 2017;17:495.

12. Vázquez-Rivera M. B-VCP, Monsanto H et al. Estudio retrospectivo que evalúa la carga de la varicela en México en menores de 1-14 años de edad [Retrospective Study Assessing the Burden of Varicella in México in Children 1-14 Years of Age]. . Acta Paediatr de México Forthcoming 2018.

13. Wysocki J, Malecka I, Stryczynska-Kazubska J, et al. Varicella in Poland: economic burden in children 1-12 years of age in Poland, 2010-2015. BMC Public Health. 2018;18:410.

14. Versporten A, Bielicki J, Drapier N, et al. The worldwide antibiotic resistance and prescribing in European children (ARPEC) point prevalence survey: developing hospital-quality indicators of antibiotic prescribing for children. $J$ Antimicrob Chemother. 2016;71:1106-17.

15. Hersh AL, Shapiro DJ, Pavia AT, et al. Antibiotic prescribing in ambulatory pediatrics in the United States. Pediatrics. 2011;128:1053-61.

16. Principi N, Esposito S. Antimicrobial stewardship in paediatrics. BMC Infect Dis. 2016;16:424

17. Akhloufi $H$, Streefkerk RH, Melles DC, et al. Point prevalence of appropriate antimicrobial therapy in a Dutch university hospital. Eur J Clin Microbiol Infect Dis. 2015;34:1631-7.

18. Ceyhan M, Yildirim I, Ecevit C, et al. Inappropriate antimicrobial use in Turkish pediatric hospitals: a multicenter point prevalence survey. Int J Infect Dis. 2010;14:e55-61.

19. Hariharan S, Pillai G, Mclntosh D, et al. Prescribing patterns and utilization of antimicrobial drugs in a tertiary care teaching hospital of a Caribbean developing country. Fundam Clin Pharmacol. 2009;23:609-15.

20. Fleming-Dutra KE, Hersh AL, Shapiro DJ, et al. Prevalence of inappropriate antibiotic prescriptions among US ambulatory care visits, 2010-2011. JAMA. 2016;315:1864-73.

21. Hawn MT, Vick CC, Richman J, et al. Surgical site infection prevention: time to move beyond the surgical care improvement program. Ann Surg. 2011; 254:494-9 discussion 9-501.

22. De Luca M, Dona D, Montagnani C, et al. Antibiotic prescriptions and prophylaxis in Italian children. Is it time to change? Data from the ARPEC project. PLoS One. 2016;11:e0154662. 
23. Urbiztondo I, Bjerrum L, Caballero $L$, et al. Decreasing inappropriate use of antibiotics in primary Care in Four Countries in South America-cluster randomized controlled trial. Antibiotics (Basel). 2017;6(4):E38.

24. Valenzuela MT, de Quadros C. Antibiotic resistance in Latin America: a cause for alarm. Vaccine. 2009;27(Suppl 3):C25-8.

25. World Health Organization. Global Tuberculosis Report 2016. Available at: http://www.who.int/tb/publications/global_report/en/. Accessed 29 Mar 2018.

26. Isaacman DJ, McIntosh ED, Reinert RR. Burden of invasive pneumococcal disease and serotype distribution among Streptococcus pneumoniae isolates in young children in Europe: impact of the 7-valent pneumococcal conjugate vaccine and considerations for future conjugate vaccines. Int J Infect Dis. 2010;14:e197-209.

27. World Health Organization. Varicella and herpes zoster vaccines: WHO position paper, June 2014. Wkly Epidemiol Rec. 2014;25(89):265-88.

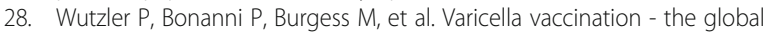
experience. Expert Rev Vaccines. 2017;16:833-43.

29. WHO vaccine-preventable diseases: monitoring system. 2017 global summary. Available from: http://apps.who.int/immunization_monitoring/ globalsummary/schedules. Accessed 29 Mar 2018.

30. Hirose $M$, Gilio $A E$, Ferronato $A E$, et al. The impact of varicella vaccination on varicella-related hospitalization rates: global data review. Rev Paul Pediatr. 2016;34:359-66.

\section{Publisher's Note}

Springer Nature remains neutral with regard to jurisdictional claims in published maps and institutional affiliations.

Ready to submit your research? Choose BMC and benefit from:

- fast, convenient online submission

- thorough peer review by experienced researchers in your field

- rapid publication on acceptance

- support for research data, including large and complex data types

- gold Open Access which fosters wider collaboration and increased citations

- maximum visibility for your research: over $100 \mathrm{M}$ website views per year

At $\mathrm{BMC}$, research is always in progress.

Learn more biomedcentral.com/submissions 